\title{
Analisis Bahan Ajar Fisika Berdasarkan Perspektif Education for Sustainable Development
}

\author{
Rina Wijayanti ${ }^{*}$, Fenny Roshayanti, Irna Farikhah, Nur Khoiri, Joko Siswanto \\ Program Studi Pasca Sarjana IPA Universitas PGRI Semarang \\ *Corresponding Author. Email: rina.wijayanti1979@gmail.com
}

\begin{abstract}
This study aims to describe the results of the analysis of physics teaching materials for high school energy sources based on the perspective of Education for Sustainable Development (ESD). The research method used is descriptive quantitative research. The population in this study were all materials in physics teaching materials for class XII in Pemalang Regency with samples of energy sources in 5 class XII teaching materials used by teachers in Pemalang Regency. The research instrument was in the form of a text / unit check list analysis based on the ESD indicator to obtain data.The results of the study found that the teaching materials used represented the ESD theme with an average appearance proportion of $21.56 \%$, for the socio-cultural aspects of $8.05 \%$, for environmental aspects $7.53 \%$ and $5.98 \%$ for economic aspects. From the results of research based on requests to develop ESD-based teaching materials on energy sources.
\end{abstract}

\begin{abstract}
Abstrak: : Penelitian ini bertujuan untuk mendeskripsikan hasil analisis bahan ajar fisika SMA materi sumber-sumber energi berdasarkan perspektif Education for Sustainable Development (ESD). Metode penelitian menggunakan jenis penelitian deskriptif kuantitatif. Populasi dalam penelitian ini yaitu semua materi pada bahan ajar fisika kelas XII di Kabupaten Pemalang dengan sampel materi sumber-sumber energi pada 5 bahan ajar kelas XII yang digunakan oleh guru di Kabupaten Pemalang. Instrumen penelitian berupa check list analisis teks/ unit yang dianalisis berdasarkan indikator ESD untuk mendapatkan data. Hasil penelitian menemukan bahwa bahan ajar yang digunakan sudah merepresentasikan tema ESD dengan persentase kemunculan rata-rata $21,56 \%$, untuk aspek sosial budaya $8,05 \%$, untuk aspek lingkungan 7,53\% dan untuk aspek ekonomi 5,98\%. Dari hasil penelitian tersebut disarankan untuk melakukan mengembangan bahan ajar berbasis ESD pada materi sumbersumber energi.
\end{abstract}

\section{Article History}

Received: 10-10-2020

Revised: 02-03-2021

Accepted: 21-04-2021

Published: 07-06-2021

\section{Key Words:}

Teaching Material,

Education for

Sustainable

Development.

\section{Sejarah Artikel \\ Diterima: 10-10-2020 \\ Direvisi: 02-03-2021 \\ Disetujui: 21-04-2021 \\ Diterbitkan: 07-06-2021}

\section{Kata Kunci:}

Bahan Ajar, Education for Sustainable Development.

How to Cite: Wijayanti, R., Roshayanti, F., Farikhah, I., Khoiri, N., \& Siswanto, J. (2021). Analisis Bahan Ajar Fisika Berdasarkan Perspektif Education for Sustainable Development. Jurnal Kependidikan: Jurnal Hasil Penelitian dan Kajian Kepustakaan di Bidang Pendidikan, Pengajaran dan Pembelajaran, 7(2), 340-345. doi:https://doi.org/10.33394/jk.v7i2.2985

https://doi.org/10.33394/jk.v7i2.2985

This is an open-access article under the CC-BY-SA License.

\section{Pendahuluan}

Bahan ajar merupakan materi pembelajaran yang disusun secara sistematis dan digunakan dalam proses pembelajaran oleh guru dan siswa (Sadjati, 2012). Bahan ajar yang berkualitas akan mendukung tercapainya pembelajaran yang efektif dan efisien. Bahan ajar yang digunakan cukup mempengaruhi berhasil atau tidaknya pencapaian tujuan pendidikan, (Sari, M. Z., Fitriyani, Y., \& Amalia, D, 2020). Sehingga dapat diartikan bahwa bahan ajar cukup diperlukan untuk mencapai pembelajaran yang efektif dan efisien dalam upaya mencapai tujuan pendidikan. Komponen pendidikan yang sangat penting dalam proses pembelajaran diantaranya adalah bahan ajar. Tersedianya bahan ajar yang bekualitas akan mendukung keberhasilan dalam proses pembelajaran. Namun bahan ajar yang ada selama ini lebih menekankan kepada dimensi konten daripada dimensi proses dan konteks. Oleh 
karenanya melalui pemilihan bahan ajar yang tepat diharapkan dapat meningkatkan pemahaman siswa tentang Education for Sustainable Development dalam upaya menjaga keberlangsungan sumber energi.

Education for Sustainable Development (ESD) merupakan pendidikan yang menyisipkan wawasan secara luas dan futuristik tentang lingkungan global untuk memberikan kesadaran kepada masyarakat agar berkontribusi dalam pengembangan berkelanjutan di masa sekarang dan masa depan dan penting termasuk dalam suatu pembelajaran (KPN, 2010). ESD menjadi hal sangat penting karena pengelolaan sumber daya alam yang dilakukan manusia ini pada saat tertentu akan mengalami kehancuran jika tidak ada pola yang diubah (Segara, 2015). ESD menanamkan pemikiran tentang kebutuhan hidup generasi sekarang tanpa mengabaikan generasi masa depan. Penanaman nilai berkelanjutan ini harus diperkenalkan sejak dini, salah satu caranya adalah dengan memperkenalkan Education for Sustainable Development di lingkungan sekolah (Segara, 2015), dengan harapan peserta didik memiliki nilai-nilai keberlanjutan sehingga mampu mempertahankan kelestarian lingkungan alam, sosial dan budaya.

Pendidikan berkelanjutan ditujukan untuk menyediakan dan memfasilitasi pembelajaran, pelatihan dan pengalamana praktis baik pada pendidikan formal maupun nonformal untuk mempersipakan pembangunan berkelanjutan dan membekali sikap peduli lingkungan (Medrick, 2013). Sesuai dengan pernyataan UNESCO bahwa pendidikan merupakan kunci dari pembangunan berkelanjutan. Adanya pendidikan diharapkan menghasilkan perubahan positif dibidang ekonomi, sosial, dan budaya. Trend perkembangan pendidikan di tingkat internasional adalah pendidikan sebagai alat penggerak pembangunan secara inklusif dan berkelanjutan (Burns et.all, 2019). ESD menekankan pada langkahlangkah transmisi informasi, perubahan sikap, dan perubahan perilaku. Pendidikan pembangunan berkelanjutan menghasilkan pengetahuan melalui tindakan kritis dan refleksi, perubahan kebijakan dan praktik penerapan. Pendidikan pembangunan berkelanjutan akan menghasilkan warga negara yang aktif dan kritis (Shohel, 2011). Hal ini diperkuat oleh pernyataan PBB (2018) pembangunan berkelanjutan mengedepankan Pendidikan. Pendidikan memiliki peran sebagai dasar pembangunan berkelanjutan (Avelar, 2019). Menurut Kemendiknas (2010) perspektif Education for Sustainable Development (ESD) memiliki tiga aspek yaitu sosial- budaya, lingkungan, dan ekonomi. Jika nilai-nilai ESD pada komponenkomponen perspektif dilaksanakan, maka akan tercapai pembangunan berkelanjutan. Perspektif dari tiga aspek tersebut terdiri dari 15 komponen sebagai berikut:

Tabel 1. Komponen Tiga Aspek ESD

\begin{tabular}{|c|c|c|}
\hline Sosial-Budaya & Lingkungan & Ekonomi \\
\hline 1) Hak Asasi Manusia & 1) Sumber daya alam & 1) Pengurangan \\
\hline 2) Keamanan & 2) Perubahan cuaca & kemiskinan \\
\hline 3) Kesetaraan gender & 3) Pembangunan pedesaan & 2) Tanggung \\
\hline 4) Keragaman budaya dan & 4) Urbanisasi berkelanjutan & perusahaan \\
\hline pemahaman lintas budaya & 5) Pencegahan dan penaganan & 3) Ekonomi pasar \\
\hline 5) Kesehatan & bencana & \\
\hline 6) HIV/AIDS & & \\
\hline 7) Tata Kelola & & \\
\hline
\end{tabular}

Sumber: UNESCO and Sustainable Development (2005)

Bahan ajar merupakan materi pembelajaran yang disusun secara sistematis dan digunakan dalam proses pembelajaran oleh guru dan siswa (Sadjati, 2012). Bahan ajar yang berkualitas akan mendukung tercapainya pembelajaran yang efektif dan efisien. Menurut BSNP (2010), terdapat beberapa kriteria bahan ajar yang berkualitas, yaitu mengacu pada 
kompetensi dasar, berisi pengetahuan tertulis sesuai dengan tahap kognitif siswa, berisi konsep-konsep yang disajikan secara interaktif dan menstimulus adanya proses berfikir kritis serta kreatif, dan tampilan yang disajikan menarik.

Adapun tujuan dari penelitian ini adalah untuk menganalisis muatan ESD yang tedapat pada pada bahan ajar fisika yang digunakan di sekolah-sekolah. Terdapat tiga aspek utama dalam perspektif ESD yaitu aspek sosial budaya, lingkungan dan ekonomi yang dapat diintegrasikan dalam bahan ajar materi sumber-sumber energi yang meliputi keterbatasan energi dan dampaknya bagi kehidupan, dampak keterbatasan energi dan energi alternatif (Wijayanti, R., \& Siswanto, J, 2020).

\section{Metode Penelitian}

Penelitian ini menggunakan metode deskriptif. Langkah awal dalam penelitian ini adalah melakukan survey bahan ajar fisika yang digunakan di sekolah-sekolah negeri di Kabupaten Pemalang, yaitu SMA Negeri 1 Randudongkal, SMA Negeri 1 Moga, SMA Negeri 1 Belik dan SMA Negeri 3 Pemalang. Langkah berikutnya yaitu memilih lima bahan ajar fisika yang paling banyak digunakan oleh siswa dan guru di sekolah-sekolah tersebut. Obyek penelitian ini adalah bahan ajar fisika kelas XII pada materi sumber-sumber energi. Daftar unsur-unsur teks/ unit yang dianalisis pada bahan ajar tersebut yaitu paragraf-paragraf, pertanyaan-pertanyaan, gambar-gambar, tabel-tabel beserta keterangannya, komentarkomentar singkat yang lengkap. Daftar halaman yang tidak perlu dianalisis dalam buku ajar seperti halaman yang mengandung ulasan atau kosa kata, dan pencapaian tujuan serta sasaran (Chiappetta et.all, 1991). Pada tahap pengumpulan data langkah-langkah yang dilakukan adalah sebagai berikut:

1) Menganalisis setiap pernyataan pada halaman yang dianalisis dan mencocokannya dengan indikator ESD yang ada pada lembar check list

2) Menjumlahkan kemunculan indikator ESD pada setiap bahan ajar yang dianalisis

3) Menghitung persentase kemunculan indikator ESD untuk setiap perspektif

Persentase perspektif Education for Sustainable Development $(\mathrm{ESD})=$

$$
\text { Persentase }=\frac{\text { jumian makator tuap aspek }}{\text { jumian Enakator total aspek }} \times 100 \%
$$

Selanjutnya dilakukan analisis data untuk mengetahui skor rerata setiap indikator. Analisis ini bertujuan untuk mengetahui seberapa besar pespektif ESD pada bahan ajar.

\section{Hasil Penelitian dan Pembahasan}

Hasil dari penelitian yang dilakukan merupakan persentase kemunculan indikator ESD pada bahan ajar yang dianalisis yang meliputi aspek sosial budaya, lingkungan dan ekonomi pada materi sumber energi sesuai dengan tabel 1. Berikut hasil analisis data penelitian dan pembahasannya:

Tabel 2. Persentase Kemunculan Tiap-tiap Aspek dalam Perspektif ESD untuk Setiap Bahan Ajar

\begin{tabular}{|c|c|c|c|c|c|c|c|}
\hline \multirow[b]{2}{*}{ No } & \multirow[b]{2}{*}{ Aspek ESD } & \multicolumn{5}{|c|}{ Kemunculan (\%) } & \multirow[b]{2}{*}{$\begin{array}{c}\text { Rata-rata } \\
(\%)\end{array}$} \\
\hline & & $\begin{array}{l}\text { Bahan } \\
\text { Ajar A }\end{array}$ & $\begin{array}{l}\text { Bahan } \\
\text { Ajar B }\end{array}$ & $\begin{array}{l}\text { Bahan } \\
\text { Ajar C }\end{array}$ & $\begin{array}{l}\text { Bahan } \\
\text { Ajar D }\end{array}$ & $\begin{array}{l}\text { Bahan } \\
\text { Ajar E }\end{array}$ & \\
\hline 1. & Sosial Budaya & 15,58 & 10,39 & 0 & 3,89 & 10,39 & 8,05 \\
\hline 2. & Lingkungan & 7,79 & 9,09 & 3,89 & 9,09 & 7,79 & 7,53 \\
\hline 5. & Ekonomi & 11,69 & 2,60 & 3,39 & 6,50 & 5,20 & 5,98 \\
\hline
\end{tabular}

Tabel 2 menunjukkan persentase kemunculan tiap-tiap aspek dalam perspektif ESD Development pada setiap bahan ajar. Berdasarkan hasil penelitian tersebut, diperoleh rata-rata Jurnal Kependidikan Vol. 7. No. 2 : Juni 2021 
persentase kemunculan tiga aspek dalam perspektif ESD yaitu perspektif sosial budaya $8,05 \%$, pespektif lingkungan 7,53\% dan perspektif ekonomi 5,98\%. Dari data tersebut perspektif sosial budaya yang terdapat pada bahan ajar mempunyai rata-rata persentase yang paling tinggi dibandingkan dengan perspektif lingkungan dan ekonomi.

Aspek sosial-budaya pada ESD: hak azasi manusia, keamanan, kesetaraan gender, keragaman budaya dan pemahaman lintas bidaya, kesehatan, HIV/ AIDS, tata kelola merupakan aspek dengan rata-rata persentase muatan ESD paling tinggi yaitu 8,05\% diikuti dengan aspek yang lainnya yaitu aspek lingkungan 7,53\% dan paling rendah aspek ekonomi $5,98 \%$. Pada lima bahan ajar tersebut, bahan ajar A memuat aspek sosial budaya paling tinggi yaitu $15,58 \%$ disusul bahan ajar B dan E yang mempunyai persentase sama yaitu 10,39\%, kemudian bahan ajar D dengan persentase 3,89\% dan yang terakhir bahan ajar $\mathrm{C}$ dengan persentase $0 \%$ yang artinya bahan ajar tersebut tidak memuat satu pun indikator ESD. Aspek lingkungan pada ESD meliputi: sumber daya alam, peruabahan cuaca, pembangunan pedesaan dan urbanisasi berkelanjutan. Dari kelima bahan ajar diperoleh data rata-rata persentase 7,53\%, bahan ajar B dan D mempunyai persentase yang sama yaitu 9,09\%, bahan ajar A dan E mempunyai persentase $7,79 \%$, dan yang paling rendah persentasenya adalah bahan ajar $\mathrm{C}$ yaitu $3,89 \%$.

Aspek ekonomi pada ESD meliputi: pengurangan kemiskinan, tanggung jawab perusahaan (CSR) dan ekonomi pasar. Dari kelima bahan ajar yang dianalisis mempunyai rata-rata persentase yang paling rendah yaitu 5,98\%. Pada kelima bahan ajar, aspek ekonomi menunjukkan hasil paling bervariasi karena tiap-tip bahan ajar menunjukkan nilai persentase yang berbeda-beda yaitu bahan ajar A dengan persentase 11,69\%, bahan ajar B dengan persentase $2,60 \%$, bahan ajar $\mathrm{C}$ dengan persentase $3,89 \%$, bahan ajar $\mathrm{D}$ dengan persentase 6,50\%, dan bahan ajar E dengan persentase 5,20\%.

Tabel 3. Jumlah Persentase Kemunculan Tiga Aspek dalam Pespektif ESD untuk Setiap Bahan Ajar

\begin{tabular}{ccc}
\hline No & Bahan Ajar & Kemunculan $(\%)$ \\
\hline 1. & A & 35,06 \\
2. & B & 22,08 \\
3. & C & 7,78 \\
4. & D & 19,48 \\
5. & E & 23,35 \\
\hline
\end{tabular}

Tabel diatas menunjukkan jumlah persentase kemunculan perspektif Education for Sustainable Development untuk setiap bahan ajar yang meliputi aspek sosial-budaya, lingkungan dan ekonomi. Berdasarkan hasil penelitian tersebut, didapatkan rata-rata persentase pada bahan ajar A adalah 35,06\%, bahan ajar B adalah 22,08\%, bahan ajar C adalah 7,78\%, bahan ajar D adalah 19,48\%, dan bahan ajar E adalah 23,35\%. Bahan ajar A memuat perspektif ESD paling tinggi dibandingkan dengan empat bahan ajar lainnya.

Bahan ajar A, B, D dan E adalah berupa buku siswa dan bahan ajar C adalah berupa modul pengayaan. Perspektif ESD yang ditemukan dalam kelima bahan ajar tersebut muncul dari paragraf-paragraf, pertanyaan-pertanyaan, gambar-gambar, tabel-tabel beserta keterangannya, komentar-komentar singkat yang lengkap pada materi sumber-sumber energi. Aktivitas laboratorium tidak ditemukan dalam dalam analisis ini. Dari hasil analisis kelima bahan ajar tersebut menunjukkan bahwa integrasi materi dengan perspektif ESD dalam bahan ajar masih perlu ditingkatkan dalam upaya mengembangkan keberlanjutan energi. Bahan ajar yang digunakan dalam pembelajaran dengan muatan sustainability memiliki misi untuk merubah pola pikir atau perilaku siswa dalam memenuhi kebutuhan masa kini dan yang akan 
datang. Konteks pembelajaran mengarahkan pola pikir siswa untuk menyadari sebab akibat dari perilaku masyarakat dalam memenuhi kebutuhan yang dapat memberikan efek negatif pada lingkungan (Sinakou, 2018). Hal ini selaras dengan tuntutan abad 21 yang mempengaruhi semua sistem kehidupan dimana perlu diseimbangkan dengan adanya pemahaman sustainability. Sustainability merupakan strategi dan kebijakan pendidikan nasional yang memiliki peran dalam menumbuhkan pemahaman tentang keberlanjutan dan kesinambungan antara lingkungan, sosial budaya dan ekonomi (Burns et.all, 2019)

Penelitian tentang upaya mengimplementasikan ESD lembaga pendidikan di antaranya adalah sekolah (Kater-Wettstädt, 2018). Sekolah memainkan peran yang penting dalam mengembangkan dan menerapkan ESD (Tristananda, 2018)) serta sustainability pendidikan memiliki peran penting dalam merubah pola pikir, kesadaran publik terhadap keberlanjutan (UNESCO, 2005). Dengan demikian ESD penting untuk diimplementasikan di sekolah dalam upaya merubah pola pikir, kesadaran publik tehadap kebelanjutan yang dalam hal ini adalah kebelanjutan akan sumber energi.

\section{Kesimpulan}

Berdasarkan analisis hasil penelitian dan pembahasan dapat disimpulkan bahwa lima bahan ajar fisika pada materi sumber-sumber energi sudah memuat persepktif Education for Sustainable Development dengan persentase kemunculan rata-rata $21,56 \%$, untuk aspek sosial budaya 8,05\%, untuk aspek lingkungan 7,53\% dan untuk aspek ekonomi 5,98\%.

\section{Saran}

Dalam upaya menumbuhkembangkan cara berpikir kritis siswa terhadap keberlanjutan ketersediaan energi untuk masa sekarang tanpa mengorbankan generasi masa depan, maka saran yang dapat diberikan adalah bagi sekolah diharapkan menggunakan bahan ajar yang bemuatan ESD dengan persentase yang tinggi. Selanjutnya, guru perlu melakukan analisis bahan ajar pada materi fisika lain yang berbasis ESD dan mengimplementasikannya pada kegiatan pembelajaran agar peserta didik dapat mengaplikasikannya dalam kehidupan seharihari. Bagi penulis buku sebaiknya menambahkan muatan ESD pada materi sumber-sumber energi dalam penulisan bahan ajar berikutnya.

\section{Daftar Pustaka}

Avelar, A. B. A., da Silva-Oliveira, K. D., \& da Silva Pereira, R. (2019). Education for advancing the implementation of the Sustainable Development Goals: A systematic approach. The International Journal of Management Education, 17(3), 100322.

BSNP, T. P. P. (2010). Paradigma pendidikan nasional abad XXI. Jakarta: Badan Standar Nasional Pendidikan.

Burns, H. L., Kelley, S. S., \& Spalding, H. E. (2019). Teaching sustainability: Recommendations for best pedagogical practices. Journal of Sustainability Education

Chiappetta, E. L., Fillman, D. A., \& Sethna, G. H. (1991). A method to quantify major themes of scientific literacy in science textbooks. Journal of research in science teaching, 28(8), 713-725.

Kater-Wettstädt, L. (2018). How secondary-school students deal with issues of sustainable development in class. Environmental Education Research, 24(11), 1565-1580. 
Kementerian Pendidikan Nasional (KPN). (2010). Model Pendidikan untuk Pembangunan Berkelanjutan (Education for Sustainable Development/ ESD) melalui kegiatan Intrakulikuler. Jakarta: Balitbang Kemdiknas.

Medrick, R. (2013). Experiential education for change. Journal of Sustainability Education, 5(1), 2996-2.

Sadjati, I. M. (2012). Pengembangan bahan ajar.

Sari, M., Fitriyani, Y., \& Amalia, D. (2020). Analisis Bahan Ajar Keragaman Suku Bangsa dan Budaya dalam Implementasi Karakter Toleransi di Sekolah Dasar. Jurnal Kependidikan: Jurnal Hasil Penelitian dan Kajian Kepustakaan di Bidang Pendidikan, Pengajaran dan Pembelajaran, 6(3), 382-396. doi:https://doi.org/10.33394/jk.v6i3.2824

Segara, N. B. (2015). Education for sustainable development (ESD) sebuah upaya mewujudkan kelestarian lingkungan. SOSIO-DIDAKTIKA: Social Science Education Journal, 2(1), 22-30.

Shohel, M. M. C., \& Howes, A. J. (2011). Models of education for sustainable development and nonformal primary education in Bangladesh. Journal of Education for Sustainable Development, 5(1), 129-139.

Sinakou, E., Boeve-de Pauw, J., Goossens, M., \& Van Petegem, P. (2018). Academics in the field of Education for Sustainable Development: Their conceptions of sustainable development. Journal of cleaner production, 184, 321-332.

Tristananda, P. W. (2018). Membumikan Education For Sustainable Development (Esd) di Indonesia dalam Menghadapi Isu-Isu Global. Purwadita: Jurnal Agama dan Budaya, 2(2), 42-49.

UNESCO. (2005). Guidelines and recommendations for reorienting teacher education to address sustainability. Education for Sustainable Development in Action Technical Paper, no. 2.

Wijayanti, R., \& Siswanto, J. (2020). Profil Kemampuan Berpikir Kritis Siswa SMA pada Materi Sumber-sumber Energi. Jurnal Penelitian Pembelajaran Fisika, 11(1), 109113. 